\title{
Accentual Structure in Spoken English-Has It Been Overanalyzed?
}

\author{
Shahla Qojayeva ${ }^{1}$ \\ ${ }^{1}$ Backis EM Programme, Faculty of Arts, Masaryk University, Czech Republic \\ Correspondence: Shahla Qojayeva, Backis EM Programme, Faculty of Arts, Masaryk University, Vinarska 5, \\ Brno,, Czech Republic. E-mail: 22shahla@gmail.com
}

Received: April 25, 2016 Accepted: May 15, 2016 Online Published: May 25, 2016

doi:10.5539/ijel.v6n3p200

URL: http://dx.doi.org/10.5539/ijel.v6n3p200

\begin{abstract}
Pronouncing words with the correct stress plays an important role in communication. This has been investigated by different phoneticians, Torsuyev and Gibson amongst others, who have analyzed the different accentual patterns of English words and defined a large number of different accentual patterns. In this paper the author experimentally challenges the concept of complex accentual structures by investigating the pattern of standard British English speakers. Using the PRAAT program, a software package which is widely used in phonetic experimental research, the fundamental parameters of frequency of tone, intensity and time were measured and used to define accentual patterns of polysyllabic words as spoken by two modern standard English speakers. This study demonstrated that polysyllabic words, phrases and abbreviations exhibit only four distinct accentual-syllabic patterns. This is in direct contrast to previous work and demonstrates that accentual structure in spoken English has been over analyzed and made unnecessarily complex.
\end{abstract}

Keywords: stress, syllable accent, polysyllabic

\section{Introduction}

It has been acknowledged that second language learners, and even some native speakers, have difficulties in pronouncing words with the correct stress. Stress is defined as the greater degree of prominence given to one or more of its syllables and can be considered as a phonetic manifestation of accent. The syllable or syllables which are uttered with more prominence than the other syllables are said to be stressed or accented.

Stress may be called fixed, or definite, if it falls on a certain syllable in all the words of a language; but stress is said to be free if it falls on different syllables in different words. In this context, English word-stress is said to be free since it can fall on any syllable in a word. Monosyllabic words have no stress patterns, that is, they have one degree of stress.

For example, while in English there is a tendency to put the stress as near as possible to the beginning of the word, and most English words with two syllables have stress on their first syllable (basket ['ba:skit], enter ['ento], necessary ['nesəsr1]), if the first syllable is a weak prefix, the stress falls on the second syllable, (be'gin, away, be'fore) Furthermore there are also two syllable words in English that have stress on the second syllable; for example, machine [mə'fi:n], technique [tek'ni:k], indeed [in'di:d]. In most three or four-syllabic words stress falls on the third syllable from the end. The stress on the third syllable from the end is especially typical of polysyllabic verbs with the suffixes -ize, recognize ['rekəgnarz], -ly—family ['fæm?li]—ate-cultivate ['kıltıvert]

Two degrees of word stress are distinguished in English words of four or more syllables: primary and secondary. The other syllables should be unstressed. A great number of English disyllabic and polysyllabic words retain the primary or secondary stress on the root (de'claire-declaration). All English words of four or more syllables that end in suffixes "-ian" have principal stress on the syllable preceding the suffix, and secondary stress on the root syllable. For example: Utopian [ju: 'təopiə n]. In all the polysyllabic words with a primary and a secondary stress both of the stresses remain in their places if prefixes are added to the original words. (Roger Kingdon. The Groundwork of English Intonation. London, 1958)

Accentual types are created by differences in the degree of word stress as well as the distribution of the primary and secondary degrees of stress. This variability of stress in the English language has encouraged phoneticians to attempt to define different accentual patterns of English words.

For example, Gimson gave more than fifty accentual-syllabic patterns of English words for foreign learners. 
Torsuyev concluded that there were eleven accentual and more than a hundred accentual—syllabic patterns of English words. Since then numerous researchers have carried out similar analyses with differing but complex results.

The linguistic complexity of the accentual types proposed by most of these authors can be questioned. Bloomfield, for example, states that in some languages, including the English language, each word should be stressed with one primary stress (forgiving, convict). Furthermore language changes over time and this influences the classification of accentual types and makes these complex classifications of limited value. This was demonstrated by the author in an earlier analysis where the pronunciation of words within Torsuyev's accentual types were compared to the pronunciation of words in the English Pronouncing Dictionary (Daniel Jones); differences between the source materials were consistently found across all words and phrases - in polysyllabic and compound words, abbreviations and phrasal verbs. In summary, the author is of the view that a complex accentual structure of words is unnecessary.

Stress is defined by the degree of force of breath with which the vowel in the syllable is pronounced. Practically we can measure stress patterns by three types of acoustic parameters: dynamic (intensity), melodic (frequency of tone), and temporal (time).

Havel argued that the main part of the prosodic information is melodic (frequency of tone) and in fact the key role of fundamental frequency of tone in the pronunciation of lexical and syntactical units is characteristic of all Germanic languages. However Bloomfield and his colleagues maintained that all three parameters should be measured.

In this paper the author measures all three parameters to experimentally challenge the concept of complex accentual structures using all three acoustic parameters.

\section{Methodology}

The experimental material consisted of 30 compound words, 30 derivative words, 20 abbreviations, 20 abbreviations and 60 phrases. These words were recorded by two native English speakers with the standard British pronunciation. Because there is a difference in the timbre, volume and tonal frequency of voice between genders, two male speakers were chosen.

The PRAAT program was used to analyze the recordings made by the two speakers and define the accentual patterns. The PRAAT program is a software package that is widely used in phonetic experimental research to analyze, synthesize, and manipulate speech. It creates high-quality charts (oscillograms) and tables of the three acoustic parameters - fundamental frequency of tone (FFT), Intensity and time.

The results are shown below.

\section{Results}

\subsection{FFT Can Be Used to Determine Accentual-Rythmical Structure}

Table 1 shows the data output of the FFT paramenter for the word "broadseal".

Table 1. FFT analysis of the word "broadseal"

\begin{tabular}{lllll}
\hline Speakers & Parameter & \multicolumn{2}{l}{ Vowels } \\
\cline { 3 - 5 } & & $\partial$ & I \\
\hline Is. & FFT & 172 & 95 \\
\hline II s. & FFT & 152 & 115 \\
\hline
\end{tabular}

Note. D. Jones. (2006). English Pronouncing Dictionary (17th ed.).

This table shows that both speakers pronounced the word similarly; the vowel of the first syllable was pronounced with the maximum frequency of tone. The observed changes in the melodic structure (FFT) of words are the phonetic phenomena binding the vowels of the same words. This example shows how the FFT parameter can be used to identify the accentual structure of a word, in this case a word of only 2 syllables.

From the analyses of numerous other words in the experimental material it is clear that the melodic (FFT) structure by itself can often clarify the differences between the functional value of elements within words and syllables. 
However the examples below showed that FFT is essential but not sufficient to identify the accentual structure of all words.

\subsection{Both FFT and Intensity Are Necessary to Accurately Determine Accentual Strucure}

In some cases the FFT data pattern between the two speakers were different, suggesting that the two speakers pronunce words differently, for example, in the pronunciation of the polysyllabic word "intercontinental".

Table 2. Analysis of "lintercontinental"

\begin{tabular}{|c|c|c|c|c|c|c|c|}
\hline \multirow[t]{2}{*}{ speakers } & \multirow[t]{2}{*}{ Parameter } & \multicolumn{6}{|c|}{ Vowels } \\
\hline & & I & อ & $\mathrm{p}$ & I & $\mathrm{E}$ & o \\
\hline \multirow[t]{3}{*}{ I s. } & $\mathrm{T}$ & 0.06 & 0.06 & 0.08 & 0.05 & 0.08 & 0.07 \\
\hline & FFT & 152 & 190 & 126 & 116 & 96 & 94 \\
\hline & $\dot{I}$ & 77 & 79 & 79 & 79 & 77 & 66 \\
\hline \multirow[t]{3}{*}{ II s. } & $\mathrm{T}$ & 0.06 & 0.04 & 0.06 & 0.08 & 0.07 & 0.04 \\
\hline & FFT & 138 & 97 & 125 & 148 & 146 & 110 \\
\hline & $\dot{I}$ & 66 & 63 & 66 & 75 & 71 & 64 \\
\hline
\end{tabular}

Here the FFT data showed that the first speaker stressed the second syllable while the second speaker pronounced the fourth syllable. Similar differences in accentual-rhymical patterns were observed in the analysis of the word "hendecasyllable"

However, when intensity (and temporal) paramenters were considered it was clear that there were similarities in that both speakers the fourth syllable. In this example the FFT parameter was different between speakers but in other instances the reverse of this pattern was observed - the FFT parameter was the same for both speakers but the intensity differed. For example, analysis of the polysyllabic word "legislative" revealed the fact that while both speakers pronounced the first syllable of the word with the highest degree of force (FFT), this was not the case for the intensity parameters.

Similar results were found for other words in the experiemntal material. Hence, it is clear that FFT as well as intensity parameters are critical to defining an accented syllable.

It should be noted that while the temporal (time) parameter was included in the analysis of all words the overall results show that two parameters (FFT and Intensity) are sufficient and that the time parameter does not provide any additional information.

\subsection{The Simplicity of Accentual Structures}

Using both the FFT and Intensity parameters, the entire sample of polysyllablic words, phrases and abbreviations in the experiemntal material was analysed. The results of four example analyses are shown below. 

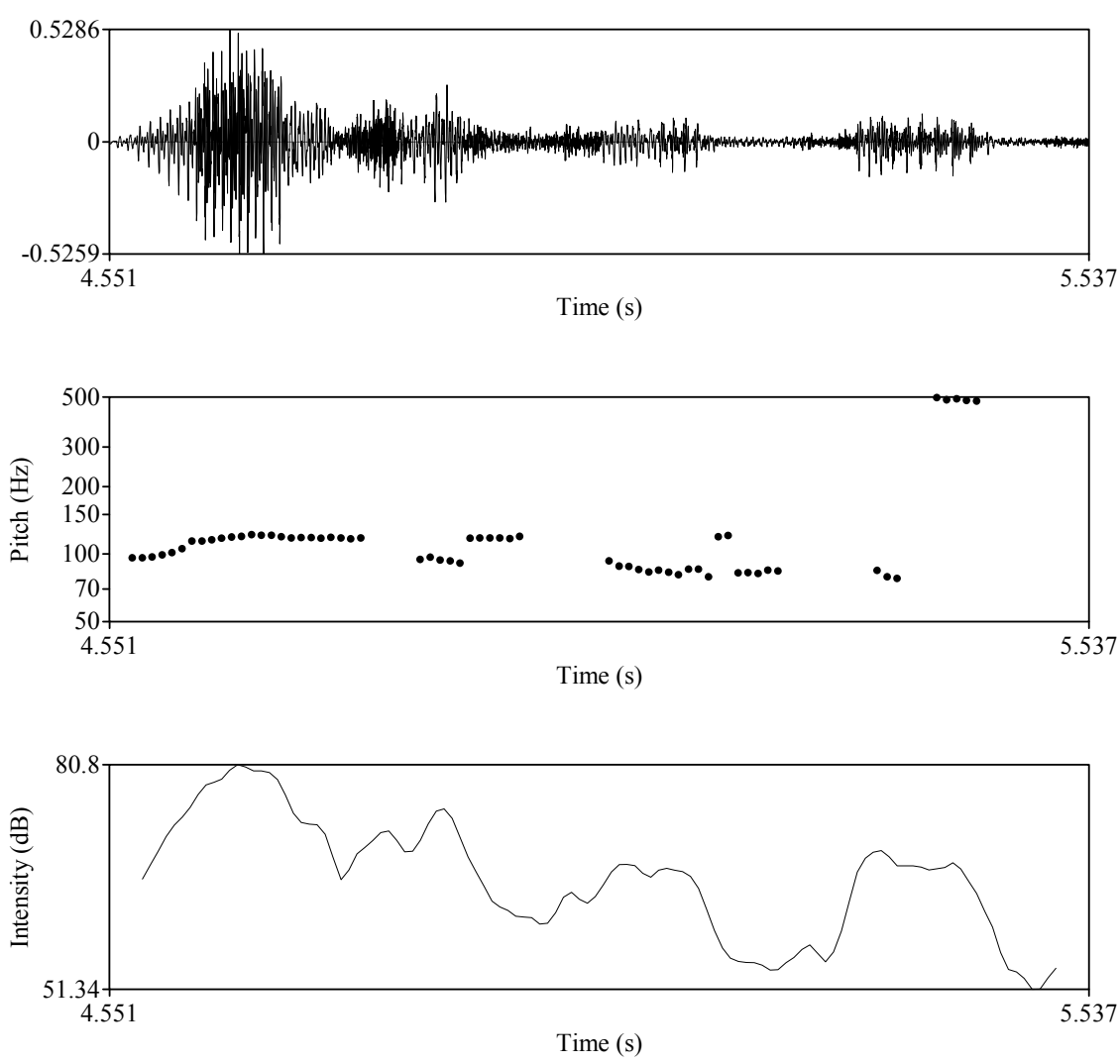

Figure 1. Analysis of the word "legislative"

This analysis shows that for this word there is one primary stress and no secondary stresses.
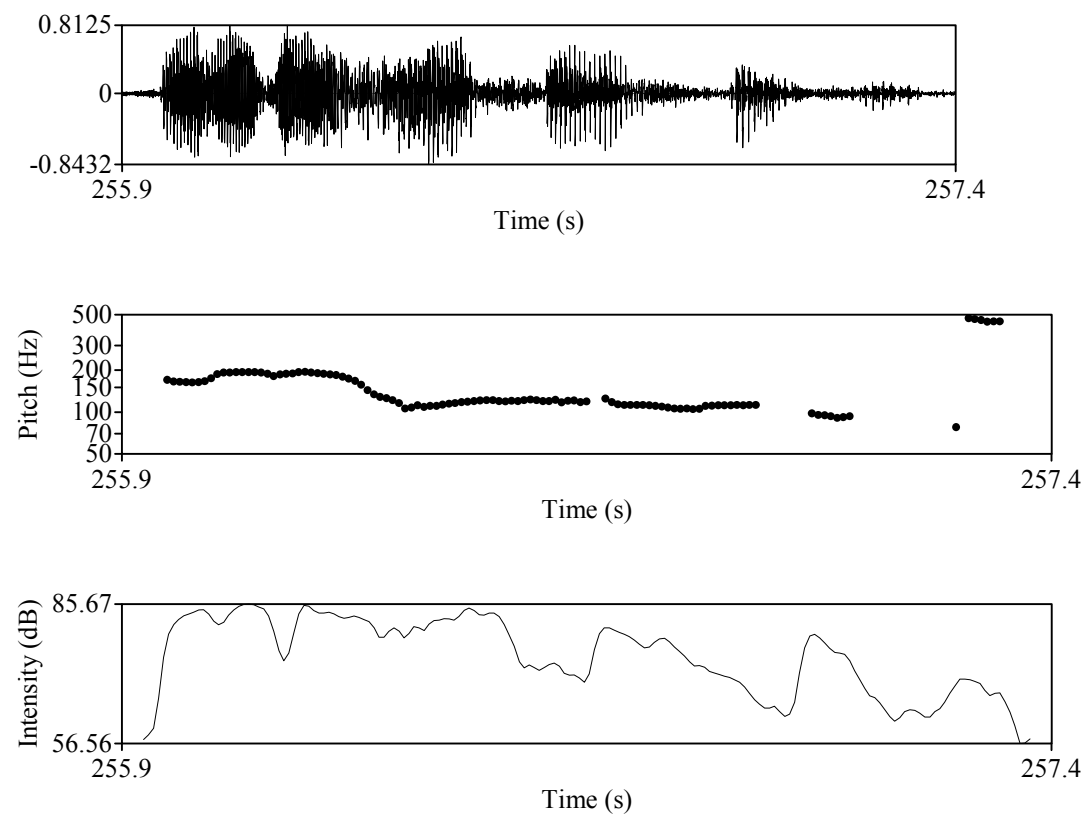

Figure 2. Analysis of the phrase "soda water bottle"

This analysis shows that for this word there is one primary stress followed by one secondary stress. 

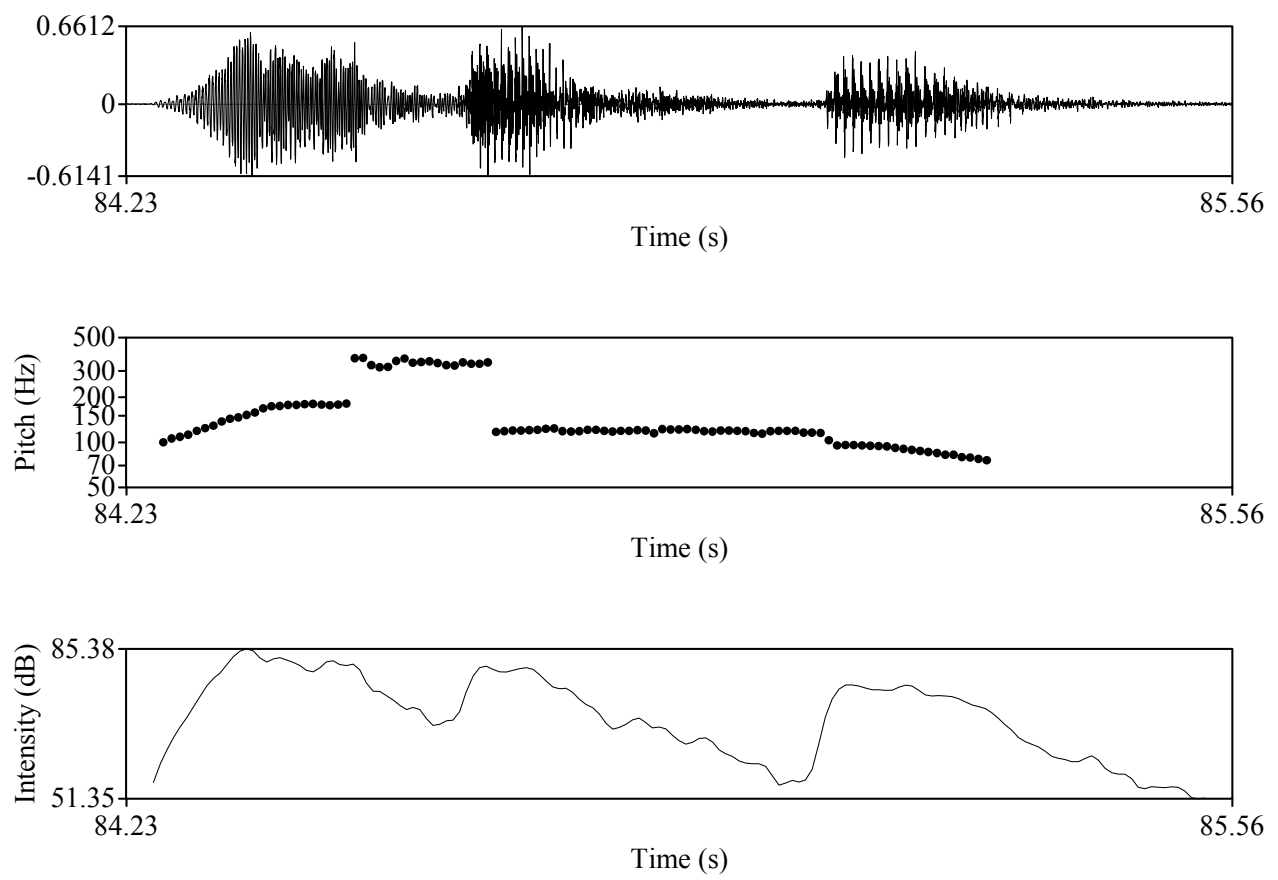

Figure 3. Analysis of the abbreviation "USA"

This analysis shows that for this word there is one secondary stress followed by one primarystress.
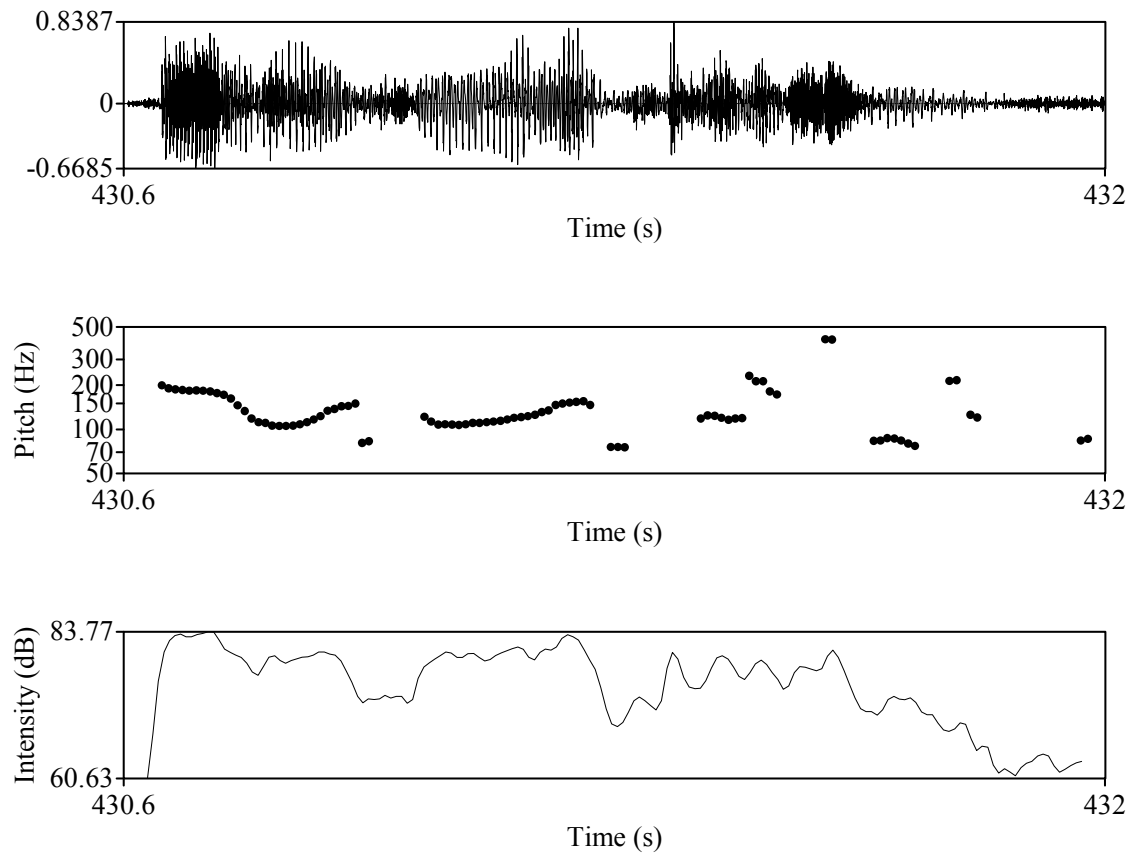

Figure 4. Analysis of the word "Telecommunication"

This analysis shows that for this word there are two secondary stresses and one primary. 
From these examples it can be seen that there are at most two stressed syllables and there are four patterns overall.

Primary

Primary followed by secondary

Secondary followed by Primary

Two secondary stress and one primary stress

These four patterns are consistently observed in the analysis of the experimental material. It needs to be emphasised that no other pattern was identified. This is the key result presented in this paper.

\section{Discussion}

The analysis of the experimental material shows that when describing the accentual patterns FFT acoustic parameters are essential but not sufficient. The main syllable which forms the accentual-rhythmical structure of polysyllabic words should be determined by both the FFT and Intensity parameters. The temporal parameter does not provide any additional discriminatory information.

Therefore both the FFT and Intensity parameters were considered in all the analyses of accentual -rhythmical structure of polysyllabic words, phrases and abbreviations.

An important obsuervation is that polysyllabic words and phrases with the same number of syllables can have different acoustic parameters. This variability of the accentual structure of English words presents great difficulty for English learners. They should be well acquainted with the accentual types of words and be aware of the modifications of accentual pattern by rhythm and temps in connected speech. Therefore, when learning English as a foreign language the acoustic parameters should be considered as well as the phoneme, phonemic combinations, morpheme, syllables etc.

For most polysyllabic words the first and the second syllable show maximum values for FFT and Intensity parameters. However in some instances the stress is on the third syllable.

In all the polysyllabic words analyzed only four distinct patterns were identified. This contrasts with the work of Gimson, Torsuyev and Bloomfield. As stated previously, Gimson gave more than fifty accentual-syllabic patterns of English words for foreign learners. Torsuyev proposed eleven accentual and more than a hundred accentual-syllabic patterns of English words.

The study showed that only four accentual-syllabic patterns need to be considered and that the previous work in this area has unnecessarily complicated what is essentially a simple construct.
A. C. Gimson. An Introdusion to the Pronunciation of English. London, 1962. p. 128.
G. P. Torsuev. Voprosi aksentologii sovremennogo angliyskogo yazika. M., 1960, pp. 41-58.

\section{Conclusion}

This study demonstrated that polysyllabic words, phrases and abbreviations exhibit only four distinct accentural-syllabic patterns.

Primary

Primary followed by secondary

Secondary followed by Primary

Secondary syllables followed by one primary stress

This is in direct contrast to previous work and demonstrated that accentual structure in spoken English has been overanalyzed and made unnecessarily complex.

\section{Acknowledgement}

Immeasurable appreciation and deepest gratitude for the help and support are extended to the following persons who is one way or another have contributed in writting this paper possible:

Backis EM Programme, for provided scholarship during a year;

Masaryk and Montpellier Universities, for giving a chance to continue my studies as a $\mathrm{PhD}$ student in the Czech Republic;

Prof. F. H. Zeynalov \& PhD. Katerina Tomkova, my supervisors, subject specialists, for their support and guadance; 
Kay Pearse, for her endless support and words of encouragement;

For unwavering moral and emotional support of my family.

\section{References}

Abberton, E. R. M., \& Foucin, A. J. (1984). Electrolaryngography. In C. Code \& M. Ball (Eds.), Clinical experimental phonetics. London: croom Helm. http://dx.doi.org/10.1002/9780470699119.ch5

Abbott, G. (1962). Development, education, and English language teaching. ELT Journal, 46(2). http://dx.doi.org/10.1093/elt/46.2.172

Abbott, G., \& Wingard, P. (Eds.). (1981). The teaching English as an International language. Glasgow: Collins.

Bloomfield, L. (1933). Language (p. 18). University of Chicago.

Bolinger, D. (1972). Accent is predictable-if you're a mind reader. Language, 48, 633-644. http://dx.doi.org/10.2307/412039

Chomsky, N., \& Halle, M. (1968). The sound pattern of English. New York: Harper and Row.

Cichocki, C., Gibbon, D., \& Richter, H. (1986). Intonation, Accent and Rhythm: Studies in Discourse Phonology. Language on JSTOR, 62(2), 461-462. http://dx.doi.org/10.2307/414696

De Gruyter. (2016). English Pronunciation for Speakers of Spanish. From Theory to Practice (pp. 262-321). (Chapter) http://dx.doi.org/10.1515/9781501510977-012; (Book) http://dx.doi.org/10.1515/9781501510977

Fant, C. G. M. (1956). On the predictability of formant level and spectrum envelopes from fromant frequencies. In H. Lunt \& H. Maclean (Eds.), For Roman Yakobson. The Hague: Mouton.

Fudge, E. C. (1984). English word-stress. London: Allen Unwin. http://dx.doi.org/10.1017/s002222670001046

Fudge, E.C. (1969). Syllable. Journal of Linguistics, 5, 253-286. http://dx.doi.org/10.1017/s0022226700002267

Gibbon, D., \& Richter, H. (1984). Intonation, accent and rhythm. Berlin: de Gruyter. http://dx.doi.org/10.1515/9783110863239

Gimson, A. G. (1962). An Introduction to the Pronunciation of English. London: Edward Arnold.

Haavel, R. (1975). On the significance of some parameters of a pirch contour. Audotory Analysis and Perception of Speech, 511-520. http://dx.doi.org/10.1016/b978-0-12-248550-3.50039-8

Halle, M. (1975). Stress Rules in English: A New version. Studies in the Science of Language, 261-276. http://dx.doi.org/10.1075/ssls.1.12hal

Jones, D. (1952). The Phoneme, Its Nature Use. Cambridge. http://dx.doi.org/10.1086/464155

Jones, D. (2006). English Pronouncing Dictionary (17th ed.). http://dx.doi.org/10.1108/09504120710738157

Kingdon, R. (1958). The Groundwork of English Intonation. London: Longman, Green and Co. LTD. http://dx.doi.org/10.1086/464647

Oxford Advanced Learner's Dictionary. (2000). Oxford University. http://dx.doi.org/10.1108/rr.2000.14.6.20.288

Roach, P. (2009). English Phonetics and Phonology. Fourth edition. http://dx.doi.org/10.3366/edinburgh/9780748625949.003.0002

Shopen, T. (2007). Language Typology and Syntactic Description. Crammatical Categories, 3, 25. Cambridge University Press. http://dx.doi.org/10.1017/cbo9780511619427

Thompson, H. (1981). Stress and salience in English; theory and practice. Palo Alto Research Centre; Xerox.

Verena, G. S., \& Stefan, R. S. (2014). Influences of Fundamental Frequency, Formant Frequencies, Aperiodicity, and Spectrum Level on the Perception of Voice Gender. Journal of Speech Language and Hearing Research, 57(1), 285. http://dx.doi.org/10.1044/1092-4388(2013/12-0314)

Zeynalov, F. H. (2012). English Practical Phonetics. Baku.

Торсуев, Г. П. (1960). Вопросы акцентологии современного английского языка, 960 (Torsuyev-Voprosi aksentologii sovremennogo anliyskogo yazika, 1960) 


\section{Copyrights}

Copyright for this article is retained by the author(s), with first publication rights granted to the journal.

This is an open-access article distributed under the terms and conditions of the Creative Commons Attribution license (http://creativecommons.org/licenses/by/3.0/). 